\title{
Perceptions on Healthy Eating, Nutrition and Obesity among Select Groups of the Population in Trinidad
}

\author{
Dimple Singh-Ackbarali ${ }^{1} \&$ Rohanie Maharaj ${ }^{1}$ \\ ${ }^{1}$ Biosciences, Agriculture and Food Technologies (BAFT) Unit, Eastern Caribbean Institute of Agriculture and Forestry \\ (ECIAF) Campus, University of Trinidad and Tobago, Piarco, Republic of Trinidad and Tobago, West Indies
}

Correspondence: Dimple Singh-Ackbarali, The University of Trinidad and Tobago, Piarco, Republic of Trinidad and Tobago, West Indies.

Received: August 3, 2017

doi:10.11114/ijsss.v5i11.2699
Accepted: September 4, $2017 \quad$ Available online: October 13, 2017

URL: https://doi.org/10.11114/ijsss.v5i11.2699

\begin{abstract}
This paper examined local self-reported perceptions on healthy eating, nutrition and obesity among select groups of the population and how these varied with gender, age, socioeconomic status/professional/educational training, and ethnicity. $97 \%$ of participant volunteers believed that what you eat is one of the most important factors for maintaining health, there were a number of attitudinal and perceived environmental barriers to healthy eating and increasing physical activity. Results showed that while $85.8 \%$ of participant volunteers declared that they would like to get in better shape $65.8 \%$ reported that they are currently trying to improve their weight and $48.3 \%$ confessed to having poor or only ok eating habits. Busy schedule, cost of healthy foods and lack of convenience to eat or shop healthy were found to be the main barriers to healthy eating. There are significant differences in these barriers for the different age categories. The lack of motivation to do physical activity, insufficient support from friends, and lack of time to do physical activity were the main barriers to physical activity. The difference between the different age categories were significant for several of the barriers while the difference between males and females was only significant for one barrier. Finally it was found that the perceived barriers to healthy eating and physical activity did not vary by socio-economic status or overweight status. A limitation of this study was that the barriers were not assessed objectively, but rather through self-reports. It can be concluded that more efficient measure to reduce obesity might require a shift away from the traditional focus on individual behavior change towards strategies which deal with the environment in which such behaviors occur. The successful challenge to obesity therefore lies not in interventions at the individual level but in the public policy domain.
\end{abstract}

Keywords: obesity, ideal weight, obese, barriers, nutrition, healthy eating, physical activity

\section{Introduction}

Poor nutrition and diet are major public health concerns, as it can lead to being o verweight, obese and a number of chronic diseases or health concerns (Satia, 2009; Popkin, Adair \& Ng, 2012). In many de veloped countries, overweight individuals and obesity have reached epidemic proportions (Sundquist, 1998; Caribbean Food and Nutrition Institute, 2004; Bhurosy \& Jeewon, 2014). In developing countries obesity usually co-exists with under nutrition and a study done by Kohl et al. (2012) for the Lancet found that $62 \%$ of the world's overweight or obese population live in developing countries. While the Lancet study did not theorize about the why other publications have put forward that obesity trends in both developed and de veloping nations are linked to; transition in diets to more energy dense foods, decreased physical activity as well as other environmental and socioeconomic factors (WHO, 2016; Caballero, 2007; Popkin, Adair \& Ng, 2012; Satia, 2009; Bhurosy, \& Jeewon, 2014). In the Caribbean more than $60 \%$ of the adult population is currently overweight and many children are at increased risk of obesity (Henry, 2016). The risk of weight gain and the de velopment of obesity is a major contributing factor of increased risk of a range of chronic medical conditions globally (Kumanyika et al., 2002). It underlies most cases of hypertension, type-2 diabetes and the rapid increase in obesity has been accompanied by increased mortality in diabetes and hypertension (Ford, Giles, \& Dietz, 2002; Henry, 2016).

Dr. Theo Poon King, made a prediction, over 50 years ago, about the increase in obesity in Trinidad and Tobago population and now according to the Food and Agriculture Organization (FAO) statistics, Trinidad and Tobago is the $5^{\text {th }}$ fattest Nation in the world (FAO, 2013). According to the Ministry of Health, Trinidad and Tobago; over 55.7\% of the population ages 15-64 years was overweight or obese, there was a marked increase in obesity over the age of 24 years. The 
country's statistics also has that $34 \%$ of females are overweight while $32 \%$ are obese and $40 \%$ of males are overweight while $19 \%$ are obsess (2012). The ministry's report used data from a 2011 STEPS NCD risk factor survey which also showed that there was a difference in the amount of physical activity and linked their findings of males spending more time than women on physical activity as a possible reason a higher percentage of females are obese when compared to men. The nation's statistics follows the trend in other studies where women have been identified as a high risk group for weight gain and de velopment of obesity (Odom, 2006; Batson, Teelucksingh, Maharaj, \& Cockburn, 2014) and also that women tend to have higher rates in developing countries and in de veloped countries the rates were higher for men (Kohl et al., 2012).

World health Organisation estimated that in 2014 more than 1.9 billion adults ( $>18$ years of age) were overweight; at least 600 million of these persons are obese and 41 million children under the age of 5 were either overweight or obese (WHO, 2016). Increased physical activity and healthy eating habits are being promoted by many countries as the strategy for reversing the current global epidemic of an overweight and obese population (Andajani-Sutjahjo et al., 2004; Schwiebbe, 2011; Glickman et al., 2012). Many of these health promotion strategies are driven by a country's government and usually encourage individuals to consume diets that are low in fat, high in fiber and rich in fruits and vegetables, and encourages individuals to undergo moderate physical activity for at least 30-minutes five days/week (NHMRC, 2003). According to the WHO (2003) the physical activity recommendation for adults aged 18-64 is a weekly minimum of; one hundred and fifty (150) minutes of moderate aerobic activity such as cycling, swimming or brisk walking, or seventy five (75) minutes of vigorous aerobic activity such as running, or an equi valent mix of moderate- and vigorous-intensity activity. In many countries today there are many persons, young and old who still do not meet the current physical activity recommendations and/or have less than optimal diets (WHO, 2000; Kohl et al., 2012). This may be because many persons do not consider the kinds of lifestyle changes that are being recommended as feasible for them in the context of their daily lives (Ball, Crawford \& Warren, 2004). An understanding of the perceived barriers faced by the population in achieving healthy lifestyle changes is therefore important.

The perceived barriers faced by the different sexes and persons from different age groups are likely to differ from those faced by the other demographic groups. These perceived barriers may also vary according to persons of different socio economic status; persons of lower socioeconomic status (SES) who may have poorer access to parks, walking or jogging trails, and gym equipment than those of higher SES. A number of studies have suggested that a lack of knowledge is a greater barrier to eating a healthy diet among those of lower education level (Lappalainen et al., 1997, Andajani-Sutjahjo et al., 2004; Bhurosy \& Jeewon, 2014). Being overweight can also be perceived as a significant barrier to physical activity (Andajani-Sutjahjo et al., 2004). However it is not known whether or not these factors are perceived as barriers to physical activity and healthy eating among the different demographic groups in Trinidad.

Understanding consumer perceptions toward diet and nutrition is critical to advancing nutrition-related population health interventions to address such issues. The purpose of the questionnaire and this paper will be to examine local perceptions on healthy eating, nutrition and obesity among select groups of the population. This study examined self-reported perception, opinions and habits of participants and how these varied with age, socioeconomic status/professional/educational training, and ethnicity. The study also examined self-reported range of perceived barriers to physical activity and healthy eating for weight maintenance among different age groups and gender.

\section{Methods}

A questionnaire was used to capture information over a period of one month. The questionnaire was administered to individuals along transport hubs in the east west corridor in Trinidad. There was an attempt to obtain a random sample by issuing the survey to every twentieth person. The survey had questions that were designed for alternate form reliability to ensure that the individual produced similar answers and perceptions and to ensure reliable data would be collected. Participants were requested to independently answer the questions on the questionnaire and to respond as accurately as possible to the questions by either choosing the answer that they believed best matched their opinion or beliefs or giving accurate descriptions/statements. One hundred and fifty participant volunteers were invited to complete the survey and one hundred and twenty fully completed surveys were returned. Participants were asked questions on their socio-demographic background, to self-report their height and weight and this information was used to calculate body mass index $\left(\mathrm{BMI}=\left(\right.\right.$ weight $(\mathrm{kg}) \div$ height $\left.\left(\mathrm{m}^{2}\right)\right)$. Self-reported height and weight have been shown to provide a reasonably valid measure of actual height and weight for the purpose of investigating relationships in epidemiological studies (Spencer, 2002). Perceptions of barriers to weight maintenance and health were assessed by looking at those related to physical activity and those to healthy eating.

Data were first entered in an Excel file and then analyzed statistically using SPSS 22.0. Initially, descriptive analyses were performed to describe the proportion of populations, self-reported opinions and practices of the general population. Student's t-tests was done comparing self-reported classification of weight between the different genders, age groups, 
education/training categories as well as on their perceptions and opinions on body image, weight and shape. ANOVA was done comparing calculated BMIs between the different ethnic groups and also their perceptions and opinions on body image, weight and shape. Chi-square test was used to examine the association between; males and females and between younger to middle aged ( $<20$ - 40 years) and o ver middle aged (41- 65+ years) participant volunteers in healthy eating and physical activity barriers.

3. Results

\subsection{Demographic Characteristics of Participants}

The number of participant volunteers was 120 ( $n=58$ women and $n=62$ men) who ranged in age from $<20$ to $65+$ years (70.83\% were between the ages of 21 to 40). Forty one percent identified themselves as African ethnicity, while $26.7 \%$ and $32.5 \%$ identified themselves as East Indian ethnicity and mixed race respectively. Approximately $48 \%$ had tertiary level education/training and $51.7 \%$ had either a secondary level education or less (Table 1).

Table 1. Demographic characteristics of survey participants

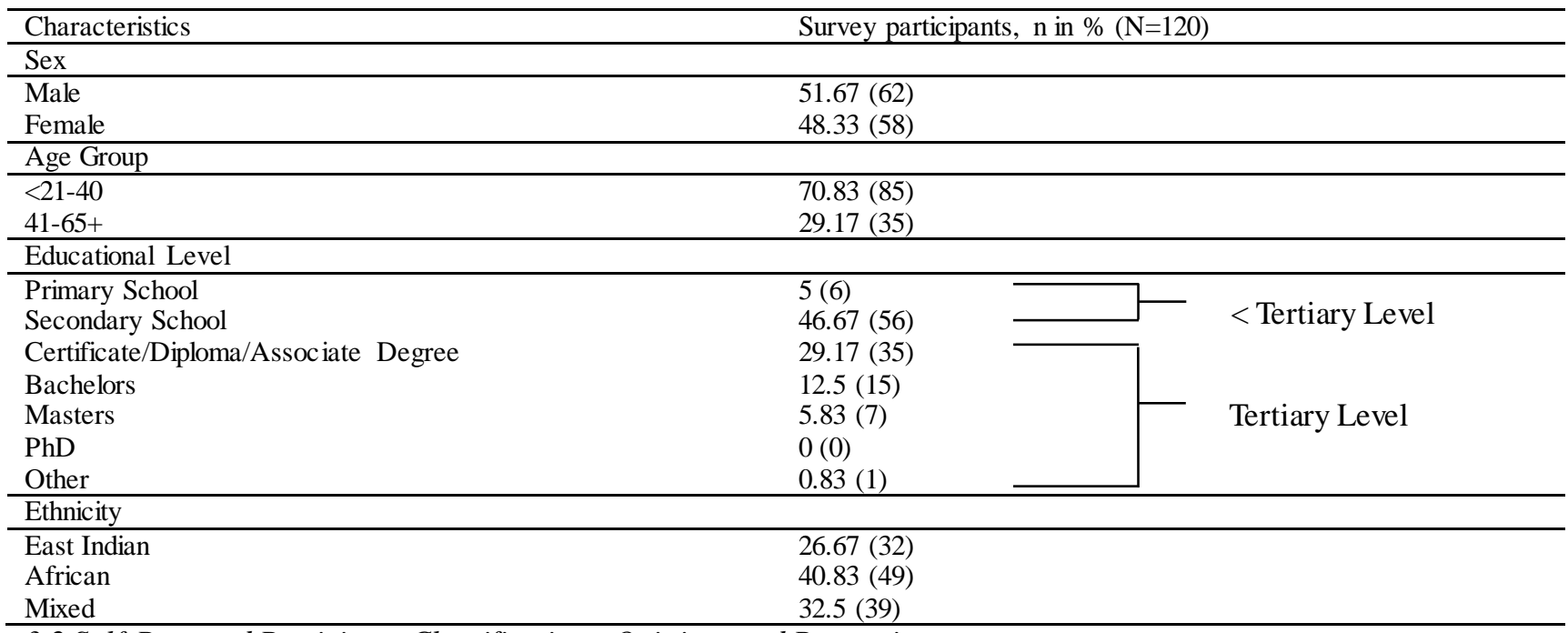

\subsection{Self-Reported Participant Classifications, Opinions and Perceptions}

Table 2. Self-reported weight status/classification of participants, $\mathrm{n}$ in $\%$ and $(\mathrm{N})$

\begin{tabular}{|c|c|c|c|c|c|}
\hline & \multicolumn{5}{|c|}{ Perception of weight, $\mathrm{n}$ in \% (N) } \\
\hline & $\begin{array}{l}\text { Slightly } \\
\text { Underweight }\end{array}$ & Ideal weight & $\begin{array}{l}\text { Slightly } \\
\text { Overweight }\end{array}$ & Very Overweight & Obese \\
\hline Total Population $(\mathrm{N}=120)$ & $5.8(7)$ & $40(48)$ & $36.7(44)$ & $11.7(14)$ & $5.8(7)$ \\
\hline Male, $(\mathrm{N}=62)$ & $6.5(4)$ & $46.8(29)$ & $33.9(21)$ & $8.1(5)$ & $4.8(3)$ \\
\hline Female, $(\mathrm{N}=58)$ & $5.2(3)$ & $32.8(19)$ & $39.7(23)$ & $11.5(9)$ & $6.9(4)$ \\
\hline $\begin{array}{l}\text { Under middle age category } \\
(\mathrm{N}=85)\end{array}$ & $9.1(6)$ & $59.1(39)$ & $42.4(28)$ & $16.7(11)$ & $1.5(1)$ \\
\hline $\begin{array}{l}\text { Above middle age category } \\
(\mathrm{N}=35)\end{array}$ & $0(0)$ & $40(14)$ & $40(14)$ & $8.6(3)$ & $11.4(4)$ \\
\hline$<$ Tertiary education, $(\mathrm{N}=62)$ & $3.2(2)$ & $35.5(22)$ & $40.3(25)$ & $11.3(7)$ & $9.7(6)$ \\
\hline Tertiary education, $(\mathrm{N}=58)$ & $8.6(5)$ & $44.8(26)$ & $32.8(19)$ & $12.1(7)$ & $1.7(1)$ \\
\hline African ethnicity, $(\mathrm{N}=49)$ & $10.2(5)$ & $44.9(22)$ & $34.7(17)$ & $8.2(4)$ & $2(1)$ \\
\hline East Indian ethnicity, $(\mathrm{N}=32)$ & $3.1(1)$ & $50(16)$ & $34.4(11)$ & $6.3(2)$ & $6.3(2)$ \\
\hline Mixed race, $(\mathrm{N}=39)$ & $2.6(1)$ & $25.6(10)$ & $41(16)$ & $20.5(8)$ & $10.3(4)$ \\
\hline
\end{tabular}

The data compiled from the surveys and presented in table 2 indicates that the majority of the total population believed that they were either an ideal weight $(40 \%)$ or only slightly overweight $(36.7 \%)$. The least popular perception of the participants with respect to their weight status/classification were either that they were slightly underweight $(5.8 \%)$ or obese $(5.8 \%)$ or perceived themselves as very overweight $(11.7 \%)$.

Student's t-test was done on each pair of means for gender, age category and education/training to determine if there were any differences in perception of weights of participants for these different demographic categories. The results of the statistical analyses showed that $\mathrm{p}>0.05$ for the comparisons between gender, age groups and training, thus we should fail to reject the null hypothesis, Ho: $\mu$ male $=\mu$ female $=\mu$ under middle age $=\mu$ middle aged and above $=\mu<$ tertiary education $=\mu$ tertiary education.

ANOVA was used to compare perception of weight between ethnic groups for the different weight perception 
classifications. The results of the statistical analyses showed that $\mathrm{p}>0.05$ and $\mathrm{F}_{\mathrm{cal}}<\mathrm{F}_{\text {crit }}$ for the different weight categories and $p>0.05$ and $F_{c a l}>F_{\text {crit }}$ for the different ethnic categories. That is there is no statistical difference in weight perception for the different ethnic categories.

Table 3. Calculated BMI, $\mathrm{n}$ in $\%$ and $(\mathrm{N})$

\begin{tabular}{|c|c|c|c|c|}
\hline & \multicolumn{4}{|c|}{ Calculated BMI, $\mathrm{n}$ in $\%(\mathrm{~N})$} \\
\hline & Underweight & Normal & Overweight & Obese \\
\hline Total Population $(\mathrm{N}=120)$ & $0.06(7)$ & $37.5(45)$ & $23.3(28)$ & $33.3(40)$ \\
\hline Male, $(\mathrm{N}=62)$ & $1.6(1)$ & $40.3(25)$ & $27.4(17)$ & $30.6(19)$ \\
\hline Female, $(\mathrm{N}=58)$ & $10.3(6)$ & $34.5(20)$ & $19(11)$ & $36.2(21)$ \\
\hline $\begin{array}{l}\text { Under middle age category } \\
(\mathrm{N}=85)\end{array}$ & $10.6(9)$ & $38.8(33)$ & $17.6(15)$ & $31.8(27)$ \\
\hline $\begin{array}{l}\text { Above middle age category } \\
(\mathrm{N}=35)\end{array}$ & $0(0)$ & $34.3(12)$ & $34.3(12)$ & $31.4(11)$ \\
\hline$<$ Tertiary education, $(\mathrm{N}=62)$ & $1.6(1)$ & $37.1(23)$ & $27.4(17)$ & $33.9(21)$ \\
\hline Tertiary education, $(\mathrm{N}=58)$ & $8.8(5)$ & $38.6(22)$ & $19.3(11)$ & $33.3(19)$ \\
\hline African ethnicity, $(\mathrm{N}=49)$ & $8.2(4)$ & $36.7(18)$ & $18.4(9)$ & $36.7(18)$ \\
\hline East Indian ethnicity, $(\mathrm{N}=32)$ & $6.3(2)$ & $43.8(14)$ & $28.1(9)$ & $21.9(7)$ \\
\hline Mixed race, $(\mathrm{N}=39)$ & $2.6(1)$ & $34.2(13)$ & $26.3(10)$ & $39.5(15)$ \\
\hline
\end{tabular}

* BMI Categories:

Underweight $=<18.5, \quad$ Normal weight $=18.5-24.9, \quad$ Overweight $=25-29.9$,

Obese $=$ BMI of 30 or greater

The mean weight for female participants was $73.9 \mathrm{~kg}(\mathrm{SD} \pm 41.4)$ and the mode weight was $65.8 \mathrm{~kg}$. The mean body mass index (BMI) among females was $26.5 \mathrm{~kg} / \mathrm{m}^{2}$ ( $\mathrm{SD} \pm 6$ ). Among male participants, the mean weight was $82.2 \mathrm{~kg}(\mathrm{SD} \pm 38)$ and the mode weight was $72.6 \mathrm{~kg}$. The mean $\mathrm{BMI}$ among males was $26.4 \mathrm{~kg} / \mathrm{m}^{2}(\mathrm{SD} \pm 5.8)$.

The mean weight for participants under the middle aged category was $76.4 \mathrm{~kg}(\mathrm{SD} \pm 19)$ and the mode weight was $65.8 \mathrm{~kg}$. The mean BMI for this demographic category was $26.1 \mathrm{~kg} / \mathrm{m}^{2}$ ( $\mathrm{SD} \pm 6.2$ ). Among participants above the middle aged category, the mean weight was $82.9 \mathrm{~kg}$ ( $\mathrm{SD} \pm 16.4$ ) and the mode weight was $72.6 \mathrm{~kg}$. The mean BMI among this demographic category was $27.9 \mathrm{~kg} / \mathrm{m}^{2}(\mathrm{SD} \pm 5.2)$.

The mean weight for participants with less than tertiary education/training was $72 \mathrm{~kg}(\mathrm{SD} \pm 41.6)$ and the mode weight was $65.3 \mathrm{~kg}$. The mean BMI for this demographic category was $26.8 \mathrm{~kg} / \mathrm{m}^{2}(\mathrm{SD} \pm 5.9)$. Among participants who received some form of tertiary education or training, the mean weight was $76.5 \mathrm{~kg}(\mathrm{SD} \pm 39.1)$ and the mode weight was $58.5 \mathrm{~kg}$. The mean BMI among this demographic category was $25.1 \mathrm{~kg} / \mathrm{m}^{2}(\mathrm{SD} \pm 6)$.

The mean weight for participants of African ethnicity was $83.3 \mathrm{~kg}(\mathrm{SD} \pm 41.8)$ and the mode weight was $65.3 \mathrm{~kg}$. The mean BMI for this demographic category was $28.6 \mathrm{~kg} / \mathrm{m}^{2}(\mathrm{SD} \pm 6.1)$. The participant volunteers who reported that they were of East Indian ethnicity, had a mean weight of $72 \mathrm{~kg}(\mathrm{SD} \pm 38.5)$ and the mode weight for this group was $72 \mathrm{~kg}$. The mean BMI among this demographic category was $24.5 \mathrm{~kg} / \mathrm{m}^{2}$ ( $\mathrm{SD} \pm 5.6$ ). Participants who reported themselves as being mixed race had a mean weight of $66.6 \mathrm{~kg}(\mathrm{SD} \pm 35.2)$ and the mode weight was $58.5 \mathrm{~kg}$. The mean BMI among this demographic category was $24.1 \mathrm{~kg} / \mathrm{m}^{2}(\mathrm{SD} \pm 5.1)$.

Table 3 shows that just over one third of the population had a normal BMI (37.5\%), one third of the total population surveyed (33.3\%) were obese and $23.3 \%$ were overweight. The results of student's t-test for gender, age categories and education/training show that there were no statistical differences between these demographic groups and the results of the ANOVA showed that there were no significant difference between the different ethnic groups for the different calculated BMI categories. 
Table 4. Self-reported weight and shape opinions of participants, $n$ in \% and (N)

\begin{tabular}{|c|c|c|c|}
\hline & \multicolumn{3}{|c|}{ Self-Reported Opinion, $\mathrm{n}$ in \% (N) } \\
\hline & $\begin{array}{l}\text { Want to get in better } \\
\text { shape }\end{array}$ & $\begin{array}{l}\text { Would like to lose weight to feel good } \\
\text { about their body image }\end{array}$ & $\begin{array}{l}\text { Trying to improve their } \\
\text { weight }\end{array}$ \\
\hline Total Population $(\mathrm{N}=120)$ & $85.8(103)$ & $65(78)$ & $65.8(79)$ \\
\hline Male, $(\mathrm{N}=62)$ & $85.5(53)$ & $54.8(34)$ & $67.7(42)$ \\
\hline Female, $(\mathrm{N}=58)$ & $86.2(50)$ & $75.9(44)$ & $63.8(37)$ \\
\hline $\begin{array}{l}\text { Under middle age category } \\
(\mathrm{N}=85)\end{array}$ & $83.5(71)$ & $58.8(50)$ & $50.6(43)$ \\
\hline $\begin{array}{l}\text { Above middle age category } \\
(\mathrm{N}=35)\end{array}$ & $91.4(32)$ & $80(28)$ & $68.6(24)$ \\
\hline$<$ Tertiary education, $(\mathrm{N}=62)$ & $82.3(51)$ & $62.9(39)$ & 62.9 (39) \\
\hline Tertiary education, $(\mathrm{N}=58)$ & $89.7(52)$ & $67.2(39)$ & $69(40)$ \\
\hline African ethnicity, $(\mathrm{N}=49)$ & $83.7(41)$ & $57.1(28)$ & $65.3(32)$ \\
\hline East Indian ethnicity, $(\mathrm{N}=32)$ & $90.6(29)$ & $71.9(23)$ & $75(24)$ \\
\hline Mixed race, $(\mathrm{N}=39)$ & $84.6(33)$ & $69.2(27)$ & $59(23)$ \\
\hline
\end{tabular}

From the total population surveyed, $85.8 \%$ want to get in better shape, $65 \%$ want to lose weight to feel good about their body image and $65.8 \%$ of the population is doing something to try and improve their weight. The more popular approaches of participants to improve their weight were through portion control, cardio exercises and self-dieting.

$45.2 \%$ males and $24.1 \%$ females indicated that they do not believe that they need to lose weight to feel good about their body image. $32.3 \%$ males and $36.2 \%$ females indicated that they do not believe that they are currently doing anything to try to improve their weight.

$41.2 \%$ participants in the under middle age category $(<20$ to 40 years) indicated that they do not believe that they need to lose weight to feel good about their body image. $49.4 \%$ participants under the middle age category indicated that they do not believe that they are currently doing anything to try to improve their weight. $20 \%$ participants in and abo ve the middle age category (41-65+ years) indicated that they do not believe that they need to lose weight to feel good about their body image. $31.4 \%$ participants in the above middle aged category indicated that they do not believe that they are currently doing anything to try to improve their weight.

$37.1 \%$ participants with less than tertiary level education/training indicated that they do not believe that they need to lose weight to feel good about their body image. $37.1 \%$ participants in this category also indicated that they do not believe that they are currently doing anything to try to improve their weight. 32.8\% participants with tertiary level education/training indicated that they do not believe that they need to lose weight to feel good about their body image. $31 \%$ participants in this category also indicated that they do not believe that they are currently doing anything to try to improve their weight. $42.9 \%, 28.1 \%$ and $30.8 \%$ participants of African, East Indian and mixed ethnicity respectfully indicated that they do not believe that they need to lose weight to feel good about their body image. $34.7 \%, 25 \%$ and $41 \%$ participants of African, East Indian and mixed ethnicity respectfully indicated that they do not believe that they are currently doing anything to try to improve their weight.

The results of student's t-test for gender, age categories and education/training show that there were no statistical differences between these demographic groups and the results of the ANOVA showed that there were no significant difference between the different ethnic groups for the different self-reported opinions of the surveyed population. 
Table 5. Self-reported personal health perceptions and habits of the participants, $(\mathrm{n}$ in \%)

\begin{tabular}{ll}
\hline Self-Reported Perception & Total Population (n in \%) \\
\hline Good/Great eating habits & $62(51.7)$ \\
Poor/Ok eating habits & $58(48.3)$ \\
Think it is very important to eat healthy & $78(65)$ \\
Think eating healthy is not too or only somewhat important & $35(29.2)$ \\
Usually/sometimes pay attention to making healthy food choices & $86(71.7)$ \\
Never/rarely pay attention to making healthy food choices & $34(28.3)$ \\
Usually/sometimes read nutrition information labels & $75(62.5)$ \\
Never/rarely read nutrition information labels & $45(37.5)$ \\
Usually/sometimes verify calories/count calories & $44(36.7)$ \\
Never/rarely verify calories/count calories & $76(63.3)$ \\
Usually/sometimes eat healthy when eating out & $86(72.3)$ \\
Never/rarely eat healthy when eating out & $33(27.7)$ \\
Eating healthy means low calorie & $29(21.2)$ \\
Eating healthy means low carbohydrate & $22(18.3)$ \\
Eating healthy means low fat & $39(32.5)$ \\
Eating healthy means low sodium & $24(20)$ \\
Eating healthy means low sugar & $27(22.5)$ \\
Eating healthy means eating fresh & $47(39.2)$ \\
Eating healthy means well balanced & $83(69.2)$ \\
Eating healthy means organic & $19(15.8)$ \\
Eating healthy means natural & $27(22.5)$ \\
Eating healthy means whole grains & $40(33.3)$ \\
Agrees what you eat influences your chance of getting a disease & $97(80.8)$ \\
\hline
\end{tabular}

Table 5 shows the self-reported opinions of participants on their awareness and habits with respect to healthy food choices. A greater percentage of the surveyed participants believe that they have great to good eating habits $(51.7 \%)$ even when they eat out $(72.3 \%)$, believe that it is very important to eat healthy $(65 \%)$ and reported that they usually/sometimes try to make healthy food choices (71.7\%) by reading nutrition information label $(62.5 \%)$ however only $36.7 \%$ of participants make an effort to verify or count calories consumed. Approximately eighty one percent of participants believes that what you eat influences your chance of getting a disease and the majority of participants agreed that eating healthy means eating a well-balanced meal (69.2\%). Least popular reported perceptions for eating healthy were consuming low carbohydrates (18.3\%) and consuming organic (15.8\%).

\subsection{Self-Reported Barriers}

Table 6: Significant differences ( $\mathrm{P}$ value) between; males and females and between the two age groups for perceived barriers to healthy eating (using chi-square test).

\begin{tabular}{|c|c|c|c|c|c|c|}
\hline Barriers & Males\% & Females $\%$ & Chi-Square & $<20$ to 40 years $\%$ & 41 to $65+$ years $\%$ & Chi-Square \\
\hline \multicolumn{7}{|c|}{ (A) Personal and environmental barriers to healthy eating } \\
\hline $\begin{array}{l}\text { (1) Do not have enough information } \\
\text { about a healthy diet }\end{array}$ & 1.6 & 13.8 & 0.015 & 9.5 & 2.8 & 0.025 \\
\hline $\begin{array}{l}\text { (2) Do not have motivation to eat } \\
\text { healthy diet }\end{array}$ & 6.5 & 12.1 & 0.310 & 11.9 & 2.8 & 0.009 \\
\hline $\begin{array}{l}\text { (3) Inconvenient to plan and shop for } \\
\text { preparing and cooking healthy foods } \\
\text { (4) Do not have access to healthy }\end{array}$ & 33.9 & 31.0 & 0.785 & 40.5 & 13.9 & 0.000 \\
\hline $\begin{array}{l}\text { foods/Healthy foods are often not } \\
\text { available when it is time for me to eat } \\
\text { (5) Not able to buy healthy foods that }\end{array}$ & 27.4 & 27.6 & 0.986 & 31.0 & 19.4 & 0.002 \\
\hline $\begin{array}{l}\text { are inexpensive } \\
\text { (6) My life is so busy that I have }\end{array}$ & 38.7 & 48.3 & 0.426 & 38.1 & 55.6 & 0.154 \\
\hline $\begin{array}{l}\text { (6) My life is so busy that } 1 \text { have } \\
\text { trouble finding time to eat properly. }\end{array}$ & 61.3 & 58.6 & 0.850 & 67.9 & 41.7 & 0.000 \\
\hline (7) Lack of self-control & 11.3 & 20.7 & 0.196 & 17.9 & 11.1 & 0.017 \\
\hline \multicolumn{7}{|c|}{ (B) Social barriers to healthy eating } \\
\hline (1) No family support to eat healthy diet & & 1.6 & 8.6 & .086 & 6.0 & 0.121 \\
\hline (2) No friends' support to eat healthy die & & 3.2 & 6.9 & .369 & 6.0 & 0.121 \\
\hline
\end{tabular}

Table 6 represents the number of participants reporting each of the perceived barriers to healthy eating in the country for males and females and participant volunteers in the two different age categories. With the exception of participant volunteers forty one years and above, "My life is so busy that I have trouble finding time to eat properly" was reported as the main personal and environmental barrier to healthy eating among both males and females and participant volunteers under forty one. The most popular reported barrier to healthy eating for participant volunteers above forty one was "Not 
able to buy healthy foods that are inexpensive". "Not able to buy healthy foods that are inexpensive" came next as a barrier to healthy eating among both males and females, while for participant volunteers under forty one this was "Inconvenient to plan and shop for preparing and cooking healthy foods" and for participant volunteers above forty one the next most popular reported barrier was "My life is so busy that I have trouble finding time to eat properly".

As for social barriers to healthy eating, "No friends' support to eat healthy diet" was the most important barrier reported by males. For females the highest reported social barrier was "No family support to eat healthy diet". For participant volunteers under and over the age of forty one no one of the social barriers rated higher than the next, howe ver a higher percentage of participant volunteers under the age of forty one had social barriers than those above the age of forty.

The significance of differences between males and females and participant volunteers in the different age categories for perceived barriers to healthy eating is presented in Tables 6 . The difference between males and females concerning "Do not have enough information about a healthy diet" was found to be highly statistically significant $(\mathrm{P}<0.05,0.015)$. However, there was great variation between participant volunteers in the different age categories for six of the seven personal and environmental barriers to healthy eating $(\mathrm{P}<0.05$, values ranged from 0.025 to 0.000$)$.

Table 7. Significant differences (value) between males and females and the two age categories for perceived barriers to physical activity (using chi-square test).

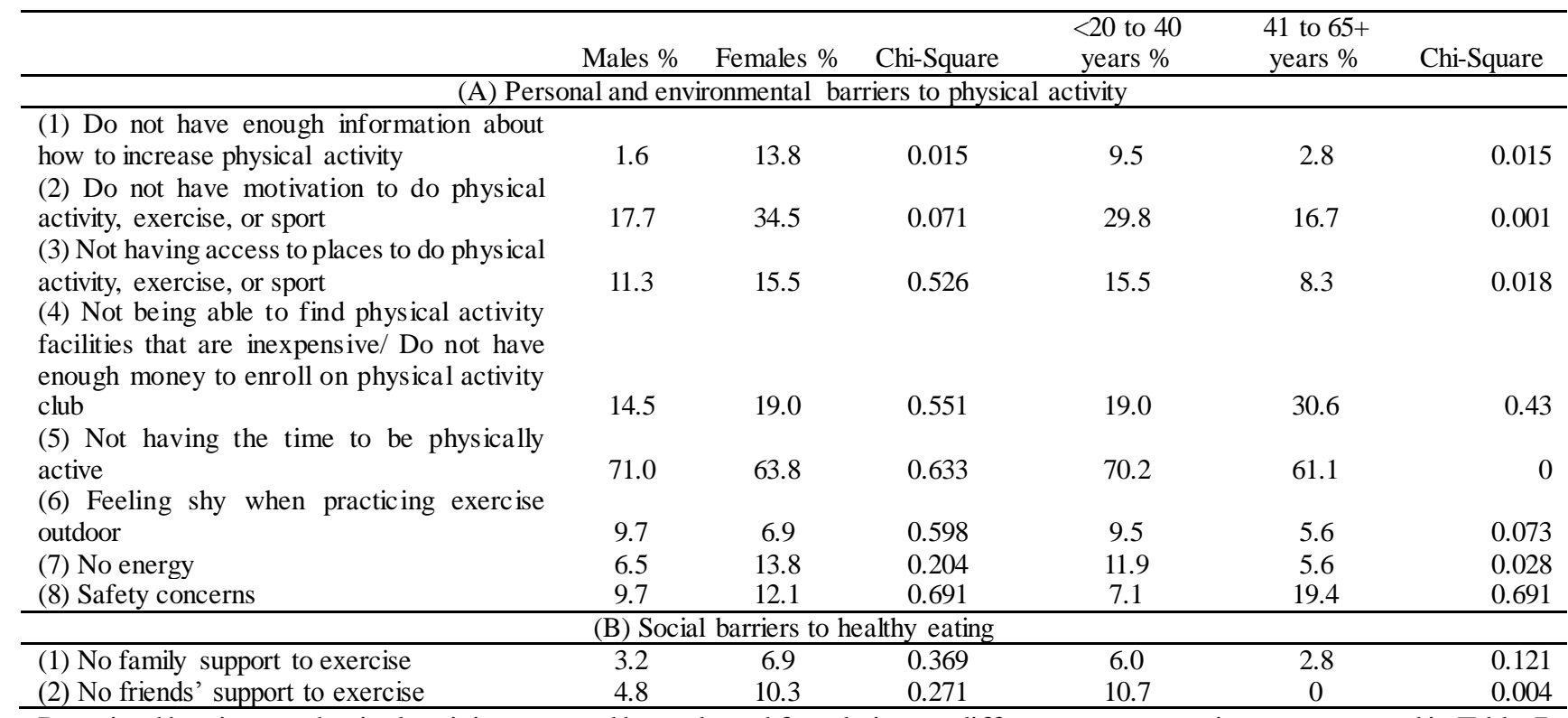

Perceived barriers to physical activity reported by male and female in two different age categories are presented in Table 7. Interestingly, "Not having the time to be physically active" was reported as the main personal and environmental barrier to physical activity among both genders and age categories. The picture was not the same for the second most popular barrier reported, both genders and participant volunteers under forty one repor ted "Do not have motivation to do physical activity, exercise, or sport" while participant volunteers over forty reported "Not being able to find physical activity facilities that are inexpensive/ Do not have enough money to enroll on physical activity club". Excluding participant volunteers over forty the most important social barrier to physical activity was reported as "No friends' support to exercise".

The differences between males and between females regarding the majority of barriers to physical activity were not significant with the exception of one of the barriers. Only the difference between males and females concerning "Do not have enough information about how to increase physical activity" was found to be highly statistically significant (0.015). Almost all the personal and environmental barriers to physical activity was significant between the different age categories, five of eight of these barriers had a $\mathrm{P}$ value $<0.05$ (values ranged from 0.028 to 0.000 ).

\section{Discussion}

Many studies on the Caribbean population have shown that people have not only altered their traditional diets in the last few decades but that they are adopting a more sedentary lifestyle and are eating too much for their level of activity (FAO, 2004; Henry, 2007; Ministry of Health Trinidad and Tobago 2012). Thus various organisations including FAO, WHO, PAHO and Caribbean government agencies have promoted education campaigns on healthy eating habits as well as healthy lifestyles. However based on this current study a significant portion of the Trinidad population is obese (33.3\%) and overweight $(23.3 \%)$. Thus the current nutritional education programmes and programmes on increasing physical activity may have little influence on changing behaviours at the individual level or may not be reaching enough of the 
population to have significant impacts. This can be attributed to the culture of the Trinidad population where encouraging people to change their behavior in order to improve their quality of diet and activity level is unlikely to succeed in an environment and culture with many inducements to engage in exactly the opposing bahaviour. Thus studies and programmes need to be developed to gather information on; environmental and social-physiological, gender and age influences on weight control behaviours.

While $80.8 \%$ of the population reported that they agree that what you eat influences your chance of getting a disease only $65 \%$ of the same population thinks that it is important to eat healthy. Results from the survey also show that while $85.8 \%$ of the surveyed population declared that they would like to get in better shape only $65.8 \%$ reported that they are currently trying to improve their weight. This again may be due to an environment and culture with many inducements to engage in exactly the opposing practices or habits, $48.3 \%$ of the participant volunteers confessed to having poor or only ok eating habits.

This study indicates that there are several personal, social, and environmental barriers to healthy eating and physical activity among the population, and there are significant differences in these barriers between participant volunteers in different age categories, however the only significant difference between males and females was not having enough information about a healthy diet. Busy schedule, cost of healthy foods and lack of convenience to eat or shop healthy were found to be the main barriers to healthy eating. Overall these findings support other research that has examined barriers to physical activity and healthy eating (Lappalainen et al., 1997; Brownson et al., 2001; Johnson, Corrigan, Dubbert \& Gramling, 1990). The demand for relatively inexpensive, ready to eat foods has grown as people especially women have less time to prepare meals (Winarno \& Allain, 2000). Shepherd et al., (2006) reported that healthy food intake is mainly associated with parents and the home environment, while fast food intake is associated with friendship and socioeconomic status. Statistics from Trinidad and Tobago Central Statistical Office reported that in $201334.5 \%$ of the female population between the ages of 15 to 24 years was employed and had a lesser income than males. Since women are the main participant volunteers responsible for preparing meals and food choices and food availability at home are mainly influenced by women then the lack of time to plan, buy and prepare healthy meals by employed females and mothers can influence and contribute to unhealthy eating habits of the entire household. Households where females are the main breadwinners can mean that economically they do not have the option of buying the healthiest ingredients or ready to eat meals for themselves or the rest of the house occupants.

This study showed that the population reported less barriers to the practice of physical activity then to eating a healthy diet. It also showed that the difference between the males and females was only significant for one barrier while the difference between the different age categories were significant for several of the barriers. The lack of motivation to do physical activity, insufficient support from friends, and lack of time to do physical activity were the main barriers to physical activity, especially among females. As with healthy eating barriers, support from friends and family for the practice of physical activity was reported as being a very low barrier. Not having the time to be physically active was the most popular reported barrier which suggests the role of work and school commitments have in overcoming barriers to weight maintenance. However the appeal of television, electronic games and computers has all increased the sedentary time of today's population. The highly significant differences between participant volunteers in different age categories in physical activity barriers in this study could be attributed to cultural and environmental factors. In general the younger population would find it more culturally and socially appealing to join a gym than the older generation and they may also be more willing to commute to parks that can facilitate outdoor physical activity.

This study shows that perceived barriers to healthy eating and physical activity did not vary by socio-economic status or overweight status. This is different from previous research studies which found that overweight men and women face a number of perceived physical activity barriers (Andajani-Sutjahjo et al., 2004; Ball, Crawford \& Owen, 2000; Shepherd et al., 2006). Similarly, given that diet varies by socio-economic status (Bolton-Smith, Smith, Woodward, \& Tunstall-Pedoe, 1991; Martikainen et al., 2003) it was expected that participant volunteers of lower socio-economic status would be more likely to experience barriers to eating a healthy diet.

Alimitation of this study was that the barriers were not assessed objectively, but rather through self-reports (i.e. perceived barriers). There were significant differences between the self-reported perception of participant volunteers weight and their calculated BMIs, only $5.8 \%$ of the population perceived themselves to be obese while $33.3 \%$ of the population had a calculated BMI of 30 or over, classifying them as obese. However it is important to consider the population's perceptions of factors hindering their efforts to engage in healthy eating and physical activity behaviours, since objective barriers may be perceived differently by different participant volunteers (e.g., poor access to a gym may be viewed as less of a barrier to physical activity between someone who walks for exercise than someone who prefers aerobics). Another limitation was that although the study achieved a somewhat modest response rate and attempts were made to sample a nationally representative sampling frame the socio-demographic profile of the population was not comparable to that of the wider national population. 


\section{Conclusion}

Although participant volunteers believe that what you eat is one of the most important factors for maintaining health, there are still a number of attitudinal and perceived environmental barriers to healthy eating and increasing physical activity. The findings of this study highlight the need for health promotion strategies that provide increased motivation, support and skills to enable women and the younger population to shop and prepare healthy, quick and inexpensive meals. Similarly, the findings suggest a need to promote more time-efficient physical activity alternatives. More efficient measure to reduce obesity might require a shift away from the traditional focus on individual behavior change towards strategies which deal with the environment in which such behaviors occur. The successful challenge to obesity therefore lies not in interventions at the individual level but in the public policy domain which can create the environment for individual behavior change.

\section{References}

Andajani-Sutjahjo, S., Ball, K., Warren, N., Inglis, V., \& Crawford, D. (2004). Perceived personal, social and environmental barriers to weight maintenance among young women: Acommunity survey. International Journal of Behavioral Nutrition and Physical Activity, 1, 15. https://doi.org/10.1186/1479-5868-1-15

Ball, K., Crawford, D., \& Owen, N. (2000). Too fat to exercise? Obesity as a barrier to physical activity. Australian and New Zealand Journal of Public Health, 24, 331-333. https://doi.org/10.1111/j.1467-842X.2000.tb01579.x

Ball, K., Crawford, D., \& Warren, N. (2004). How feasible are healthy eating and physical activity for young women? Public Health Nutrition, 7, 433-441. https://doi.org/10.1079/PHN2003541

Batson, Y. A., Teelucksingh, S., Maharaj, R. G., \& Cockburn, N. B. N. (2014). Across-sectional study to determine the prevalence of obesity and other risk factors for type 2 diabetes among school children in Trinidad, West Indies. Paediatrics and International Child Health, 34(3), 178-183. https://doi.org/10.1179/2046905514Y.0000000116

Bhurosy, T., \& Jeewon, R. (2014). Overweight and Obesity Epidemic in Developing Countries: A Problem with Diet, Physical Activity, or Socioeconomic Status? The Scientific World Journal,2014, 964236. https://doi.org/10.1155/2014/964236

Bolton-Smith, C., Smith, W. C., Woodward, M., \& Tunstall-Pedoe, H. (1991). Nutrient intakes of different social-class groups: Results from the Scottish Heart Health Study (SHHS) British Journal of Nutrition, 65, 321-335. https://doi.org/10.1079/BJN19910093

Brownson, R. C., Baker, E. A., Housemann, R. A., Brennan, L. K., \& Bacak, S. J. (2001). Environmental and policy determinants of physical activity in the United States. American Journal of Public Health, 91(12), 1995-2003. https://doi.org/10.2105/AJPH.91.12.1995

Caballero, B. (2007). The Global Epidemic of Obesity: An Overview, Epidemiologic Reviews, 29(1), 1-5. https://doi.org/10.1093/epirev/mxm012

Caribbean Food and Nutrition Institute. (2004). The Obesity Epidemic - AMajor Threat To Caribbean De velopment: The Case For Public Policies. Adapted from Paper prepared for The Caribbean Commission on Health and Development. $37(1)$.

Food and Agriculture Organization. (2004). Uses of Food Consumption and Anthropogenic Surveys in the Caribbean: How to Transform Data into Decision Making Tools. Rome.

Food and Agriculture Organization. (2013). The State Of Food and Agriculture 2013: Food Systems For Better Nutrition, Rome.

Ford, E. S., Giles, W. H., \& Dietz, W. H. (2002). Prevalence of the metabolic syndrome among US adults: Findings from the Third National Health and Nutrition Examination Survey. Journal of the American Medical Association, 287, 356-359. https://doi.org/10.1001/jama.287.3.356

Glickman, D., Parker, L., \& Sim, L. J., et al. (2012). Accelerating Progress in Obesity Prevention: Solving the Weight of the Nation. Washington(DC): National Academies Press (US); Goals, Targets, and Strategies for Change.

Henry, F. (2007). Combatting Obesity and NCDs in the Caribbean: The Policy Perspective. Calises Conference, Trinidad and Tobago, 2007.

Henry, F. J. (2016). Obesity in the Caribbean: A Case for Public Policies. J Nutr Disorders Ther 6, 194. https://doi.org/10.4172/2161-0509.1000194

Johnson, C. A., Corrigan, S. A., Dubbert, P. M., \& Gramling, S. E. (1990). Perceived barriers to exercise and weight control practices in community women. Women \& Health, 16, 177-191. https://doi.org/10.1300/J013v16n03_10 
Kohl, H. W., Craig, C. L., Lambert, E. V., Inoue, S., Alkandari, J. R., Leetongin, G., \& Kahlmeier, S. (2012). The pandemic of physical inactivity: global action for public health. The Lancet, 380(9838), 294-305. https://doi.org/10.1016/S0140-6736(12)60898-8

Kumanyika, S., Jeffery, R. W., Morabia, A., Ritenbaugh, C., \& Antipatis, V. J. (2002). Public Health Approaches to the Prevention of Obesity (PHAPO) Working Group of the International Obesity Task Force (IOTF) (2002) Obesity prevention: the case for action. Int J Obes Relat Metab Disord, 26, 425-436. https://doi.org/10.1038/sj.ijo.0801938

Lappalainen, R., Saba, A., Holm, L., Mykkanen, H., \& Gibney, M. (1997). Difficulties in trying to eat healthier: Descriptive analysis of perceived barriers for healthy eating. European Journal of Clinical Nutrition, 51, S36-S40.

Martikainen, P., Brunner, E., \& Marmot, M. (2003). Socioeconomic differences in dietary patterns among middle-aged men and women. Social Science and Medicine, 56, 1397-1410. https://doi.org/10.1016/S0277-9536(02)00137-5

Ministry of Health, Trinidad and Tobago. (2012). "Trinidad and Tobago Chronic Non-Communicable Disease Risk Factor Survey [Pan American STEPS]."

National Health and Medical Research Council (NHMRC). (2003). Dietary Guidelines for Australian Adults Canberra: Australian Government Printing Service.

Odom, J. (2006). Overweight and Obesity in Women; A literature review. Masters project, University of Arizona.

Popkin, B. M., Adair, L. S., \& Ng, S. W. (2012). Global nutrition transition and the pandemic of obesity in developing countries. Nutrition Reviews, 70, 3-21. https://doi.org/10.1111/j.1753-4887.2011.00456.x

Satia, J. A. (2009). Diet-related disparities: understanding the problem and accelerating solutions. Journal of the American Dietetic Association, 109(4), 610-615. https://doi.org/10.1016/j.jada.2008.12.019

Schwiebbe, L., Van Rest, J., Verhagen, E., Visser, R. W., Holthe, J. K., \& Hirasing, R. A. (2011). Childhood obesity in the Caribbean. West Indian Medical Journal, 60(4), 442-425.

Shepherd, J., Harden, A., Rees, R., Brunton, G., Garcia, J., Oliver, S., \& Oakley, A. (2006). Young people and healthy eating: a systematic review of research on barriers and facilitators. Health Education Research, 21(2), 239-257. https://doi.org/10.1093/her/cyh060

Sundquist, J., \& Johansson, S. (1998). The influence of socioeconomic status, ethnicity and lifestyle on body mass index in a longitudinal study. International Journal of Epidemiology, 27, 57-63. https://doi.org/10.1093/ije/27.1.57

World Health Organization. (2000). Obesity: Preventing and managing the global epidemic Report of a WHO Consultation (WHO Technical Report Series 894). Geneva: World Health Organization; 2000.

World Health Organization. (2003). Global Strategy on Diet, Physical Activity and Health: Obesity and Overweight Fact. Geneva: World Health Organization; 2003.

World Health Organization. (2016). Obesity and overweight Factsheet. Accessed from: http://www.who.int/mediacentre/factsheets/fs311/en/

Winarno, F. G., \& Allain, A. (2000). Street foods in developing countries: lessons from Asia. Rome: FAO. http://www.fao.org/docrep/U3550T/U3550T00.htm

\section{Copyrights}

Copyright for this article is retained by the author(s), with first publication rights granted to the journal.

This is an open-access article distributed under the terms and conditions of the Creative Commons Attribution license which permits unrestricted use, distribution, and reproduction in any medium, provided the original work is properly cited. 